\title{
Sorption of Cadmium in Some Soil Amendments for In Situ Recovery of Contaminated Soils
}

\author{
M. D. Carrillo Zenteno • R. C. A. de Freitas • \\ R. B. A. Fernandes • M. P. F. Fontes • C. P. Jordão
}

Received: 10 August 2012 / Accepted: 12 December 2012 /Published online: 10 January 2013

(C) Springer Science+Business Media Dordrecht 2013

\begin{abstract}
Although Cd concentrations in uncontaminated soils are usually low, pollution of soils by $\mathrm{Cd}$ from different sources of contamination pose problems. The application of soil amendments to increase plant production has been used as a viable alternative for recovery of soils contaminated with Cd. However, emphasis needs to be placed on the nature of $\mathrm{Cd}$ sorption processes in order that the amendments can be managed appropriately. A range of materials including vermicompost, sugarcane filter cake, palm kernel pie, lime, phosphate rock, and zeolite were used for the sorption studies. Total and nonspecific $\mathrm{Cd}$ sorption was estimated by batch experiments, and specific sorption was obtained by the difference between the former and the latter. Best adsorbents for specific Cd sorption from soil amendments were lime and zeolite. Langmuir adsorption isotherms fitted reasonably well in the experimental data, and their constants were evaluated, with $R^{2}$ values from 0.80 to 0.99 . The maximum adsorption capacity of $\mathrm{Cd}(\mathrm{II})$ was higher for mineral amendments than for organic
\end{abstract}

M. D. Carrillo Zenteno

Instituto Nacional Autónomo de Investigaciones

Agropecuarias (INIAP),

Km 26 vía Durán - Tambo,

Guayaquil, Guaias, Ecuador

R. C. A. de Freitas - R. B. A. Fernandes - M. P. F. Fontes •

C. P. Jordão $(\bowtie)$

Departamento de Solos, Universidade Federal de Viçosa,

36570-000 Viçosa, Minas Gerais, Brazil

e-mail: jordao@ufv.br amendments and ranged from 0.89 to $10.86 \mathrm{~g} \mathrm{~kg}^{-1}$. The small value $\left(0.08 \mathrm{~L} \mathrm{mg}^{-1}\right)$ of the constant related to the energy of adsorption indicated that $\mathrm{Cd}$ was bound weakly to the palm kernel pie. Thermodynamic parameter, the Gibbs free energy, was calculated for each system, and the negative values obtained confirm that the adsorption processes were spontaneous. The values of separation factor, $R_{\mathrm{L}}$, which has been used to predict affinity between adsorbate and adsorbent were between 0 and 1, indicating that sorption was very favorable for $\mathrm{Cd}(\mathrm{II})$.

Keywords Soil amendment - Lime - Zeolite . Sugarcane filter cake $\cdot \mathrm{Cd}$ sorption $\cdot$ Gibbs free energy

\section{Introduction}

Cadmium has no essential biological function, but the highly labile behavior of the metal in soils, especially those contaminated with relatively high concentrations, is an important factor in $\mathrm{Cd}$ accumulation in the human diet. Cadmium concentration in soil solution is established by several interactions such as adsorption, precipitation and complexation, among others. While low $\mathrm{Cd}$ concentrations in soil solution predominates organomineral adsorption, at high $\mathrm{Cd}$ concentrations and high $\mathrm{pH}$ values, precipitates of $\mathrm{Cd}$ carbonates and hydroxides could be expected to form. Interactions of heavy metals with oxides and organic matter have been described as 
the major factors influencing heavy metal mobility in acidic soils (Silveira et al. 2008).

Apart from the elevated $\mathrm{Cd}$ concentrations naturally occurring in the nature, inputs of $\mathrm{Cd}$ from the use of agricultural fertilizers, pesticides and lime, as well as industrial and domestic wastes are responsible for the major sources of $\mathrm{Cd}$ contamination in soils. Under these conditions, $\mathrm{Cd}$ can be absorbed by plants or cause groundwater contamination.

The hazard to plant, animal and human health from Cd-contaminated soils can be reduced or removed by several approaches, but economics are the crux problem with metal pollution. An alternative economically appropriate for the recovery of polluted agricultural areas with heavy metals is the remediation in situ. Bioremediation uses microorganism metabolism to remove pollutants, while phytoremediation uses living green plants for risk reduction and/or removal of contaminants from contaminated soil, water, sediment, and air. On the other hand, the use of soil amendments leads to the immobilization of the metal and results in reduced concentration and bioavailability (Oste et al. 2002). However, the choice of the amelioration and rehabilitation of metal-polluted soils techniques depends on the nature, concentration, and physicochemical characteristics of the pollutant, as well as the soil characteristics (Singh and Oste 2001).

The use of soil amendments have been an alternative for polluted agricultural areas where perennial cultures economically important are considered. Several soil amendments have been studied and include lime, agricultural gypsum, hydroxyapatite, and other soluble sources of $\mathrm{P}$, as well as Fe and Mn oxides, aluminosilicates, and biosolids with reduced metal concentrations (Hamon et al. 2002; Brown et al. 2005; Basta and McGrowen 2004). Limes, zeolites, phosphates, and organic compounds stabilize heavy metals through several chemical binding and leads to the formation of stable compounds with reduced mobility or toxicity (Kabata-Pendias 2011).

The use of biosolids and similar organic waste such as paper mill sludge is a common practice used for restoration of many sites (Sopper 1993). These amendments provide organic matter to improve soil physical properties, water infiltration, and water holding capacity. They also contain essential nutrients for plant growth. Immobilization of metals by such amendments is achieved through adsorption, complexation, and redox reactions (Adriano et al. 2004). The organic amendments interact with metals through ion exchange, superficial sorption, quelation, coagulation, and peptization (Kabata-Pendias 2011), but depending on the organic ligand and soil $\mathrm{pH}$, mobilization of the contaminant can occur. On the other hand, immobilization of heavy metal ions and complexes on inorganic amendments occurs as a result of ion exchange, surface complexation, hydrophobic interaction, and electrostatic interaction (Wahba and Zaghloul 2007).

This study aimed to evaluate $\mathrm{Cd}$ sorption in some mineral and organic amendments that are considered as promising materials for in situ recovery of contaminated soils. The approach involved aspects of spontaneity, affinity, and intensity.

\section{Materials and Methods}

The mineral and organic soil amendments used in this work included commercial samples of cattle manure vermicompost, lime, phosphate rock (Araxá), and zeolite collected from local suppliers. The other soil amendments were sugarcane filter cake, collected from a sugar mill patio in Minas Gerais State, Brazil, and palm kernel pie, from a palm plant in Bahia State, Brazil. The soil amendments were ground and sieved to separate the particles smaller than $1 \mathrm{~mm}$ to be used in the experiments. Subsamples of the organic materials were used for physico-chemical characterization (Table 1). Some characteristics of the mineral soil amendments were as follows: dolomitic lime $(\mathrm{CaO}=36 \% ; \mathrm{MgO}=14.4 \%)$; phosphate rock $\left(\mathrm{P}_{2} \mathrm{O}_{5}\right.$ total $=24 \% ; \mathrm{P}_{2} \mathrm{O}_{5}$ citric acid soluble $=3 \%$ ); zeolite (Heulandite group zeolite). The neutralizing power, reactivity, and relative power of total neutralization of lime were $97.3 \%, 68.5 \%$, and $66.6 \%$, respectively.

Total, specific, and nonspecific sorption of Cd was investigated by laboratory batch experiments. Langmuir adsorption isotherms were obtained at the natural $\mathrm{pH}$ of the materials. The experiments were conducted in $50-\mathrm{mL}$ centrifuge tubes into which were placed $0.25 \mathrm{~g}$ of soil amendment and $25 \mathrm{~mL}$ of a synthetic Cd solution containing $0,1.12,5.62,11.24,16.86$, 33.72 , or $84.30 \mathrm{mgL}^{-1} \mathrm{Cd}$ as $\mathrm{Cd}\left(\mathrm{NO}_{3}\right)_{2}$, following the procedure recommended by Pierangeli et al. (2007). The suspensions were shaken for $16 \mathrm{~h}$ at $25 \pm$ $2{ }^{\circ} \mathrm{C}$, centrifuged at $1,861 \times \mathrm{g}$ for $5 \mathrm{~min}$ and $\mathrm{Cd}$ concentrations determined in the solutions. The total sorption of $\mathrm{Cd}$ was calculated as the difference between that added and that in the supernatant. 
Table 1 Characteristics of the organic soil amendments

\begin{tabular}{|c|c|c|c|c|c|c|c|c|c|c|c|c|}
\hline Soil amendment & $\begin{array}{l}\text { Apparent } \\
\text { density } \\
\left(\mathrm{kgdm}^{-3}\right)\end{array}$ & $\begin{array}{l}\mathrm{pH} \text { in } \mathrm{H}_{2} \mathrm{O} \\
(1: 2.5)\end{array}$ & $\begin{array}{l}\mathrm{Ca} \\
\text { Cont }\end{array}$ & $\begin{array}{l}\mathrm{Mg} \\
\mathrm{nt}(\mathrm{gkg}\end{array}$ & & $\mathrm{P}$ & $\mathrm{N}$ & $\begin{array}{l}\text { Humic } \\
\text { acids }\end{array}$ & $\begin{array}{l}\text { Fulvic } \\
\text { acids }\end{array}$ & Humin & $C_{\text {total }}$ & $\mathrm{C} / \mathrm{N}$ ratio \\
\hline Vermicompost & 1.0 & 5.28 & 0.85 & 0.15 & 0.06 & 0.35 & 1.13 & 0.76 & 0.51 & 6.14 & 5.11 & 4.52 \\
\hline Sugarcane filter cake & 0.4 & 6.51 & 1.40 & 0.12 & 0.15 & 0.71 & 1.38 & 0.59 & 0.77 & 22.42 & 19.35 & 14.02 \\
\hline Palm kernel pie & 0.7 & 5.47 & 0.20 & 0.20 & 0.28 & 0.39 & 2.26 & 1.11 & 1.31 & 25.60 & 38.24 & 16.92 \\
\hline
\end{tabular}

${ }^{a}$ Nutrients, humic and fulvic acids, humin, and total carbon were determined following the procedures of Mendonça and Matos (2005)

Nonspecific Cd sorption was determined in the previous residues after washing them twice with $25 \mathrm{~mL}$ of deionized water. To the residues was added $25 \mathrm{~mL}$ of a $10 \mathrm{mmolL}^{-1} \mathrm{NaNO}_{3}$ extractant solution having $\mathrm{pH}$ adjusted to 5.5 , at the same experimental conditions as described above for the total Cd sorption (Harter and Naidu 2001).

Specific Cd sorption was calculated as the difference between the total $\mathrm{Cd}$ sorption and the nonspecific $\mathrm{Cd}$ sorption. Each experiment was replicated three times, and $\mathrm{Cd}$ concentrations were measured with a Varian atomic absorption spectrophotometer, model 220 FS. In our study, data were fitted to the nonlinear Langmuir adsorption isotherms using the software STATISTICA ${ }^{\circledR}$ (StatSoft Inc.) to estimate adsorption constants that indicate the $\mathrm{Cd}$ maximum adsorption capacity and affinity of the adsorbents.

\section{Results and Discussion}

The non-linear Langmuir isotherm is mathematically represented by the following equation:

$y=\left(a \cdot b \cdot \mathrm{C}_{\mathrm{eq}}\right) /\left[1+\left(a \cdot \mathrm{C}_{\mathrm{eq}}\right)\right]$

where $y$ is the amount of metal ion adsorbed per gram of adsorbent (milligrams per gram), $a$ is a constant related to adsorption energy (liters per milligram), $b$ is the maximum metal adsorption capacity on adsorbent (milligrams per gram), and $C_{\mathrm{eq}}$ is the metal ion concentration at the equilibrium (milligrams per liter). The $y$ value quantitatively means the monolayer adsorption capacity of an adsorbent, while $a$ is obtained from a reciprocal value of the concentration at which a half saturation of the adsorbent was attained.

The results obtained for the total Cd sorption when Langmuir isotherm was used to model experimental data showed that the shape of the lime and zeolite isotherms was of "H1" type, according to Giles classification for isotherms (Giles and Smith 1974), as shown in Fig. 1a. In the "H" type isotherm, the solute has such high affinity that, in dilute solutions, it is completely adsorbed, and the initial part of the isotherm is therefore vertical. The shape of vermicompost, sugarcane filter cake, and phosphate rock isotherms was "L2" type, indicating that the data have reached a maximum value, resulting in the presence of the plateau. L-isotherm type (or Langmuir isotherm type) shows progressive saturation of the adsorption sites, i.e., the adsorbent surface has high affinity by the adsorbate at low concentrations, but the affinity is reduced at higher concentrations (Dias et al. 2001). The palm kernel pie isotherm was also of "L2" type, but $\mathrm{Cd}$ was less adsorbed as compared with the other soil amendments.

In general, the mineral amendments showed higher $\mathrm{Cd}$ maximum adsorption capacities as compared with those of the organic amendments (Fig. 1a), although the formation of $\mathrm{Cd}$ hydroxides in the sorption process has also to be considered. The values of $\mathrm{Cd}$ maximum adsorption capacities for the soil amendments were as follows (in milligrams per gram)—zeolite, 10.86; lime, 9.22; sugarcane filter cake, 6.81; phosphate rock, 6.56; vermicompost, 3.59; and palm kernel pie, 0.89 . Maximum adsorption capacities of $\mathrm{Cd}$ in several materials have been described in the literature, such as sugarcane bagasse, 1.15 (Sanchez and Espósito 2011); teak leaves powder, 29.94 (Rao et al. 2010); coconut shell powder, 295.81; and pine bark, 16.86 (Pino and Torem 2011).

According to the Langmuir model, adsorption occurs uniformly on active sites of the adsorbent, and once an adsorbate occupies a site, no further adsorption can take place at this site (Tunali and Akar 2006). The isotherm represents the equilibrium relationship between the 
Fig. 1 Langmuir isotherms for the adsorption of $\mathrm{Cd}(\mathrm{II})$ by selected soil amendments: a total adsorption; $\mathbf{b}$ nonspecific adsorption; $\mathbf{c}$ specific adsorption (a)

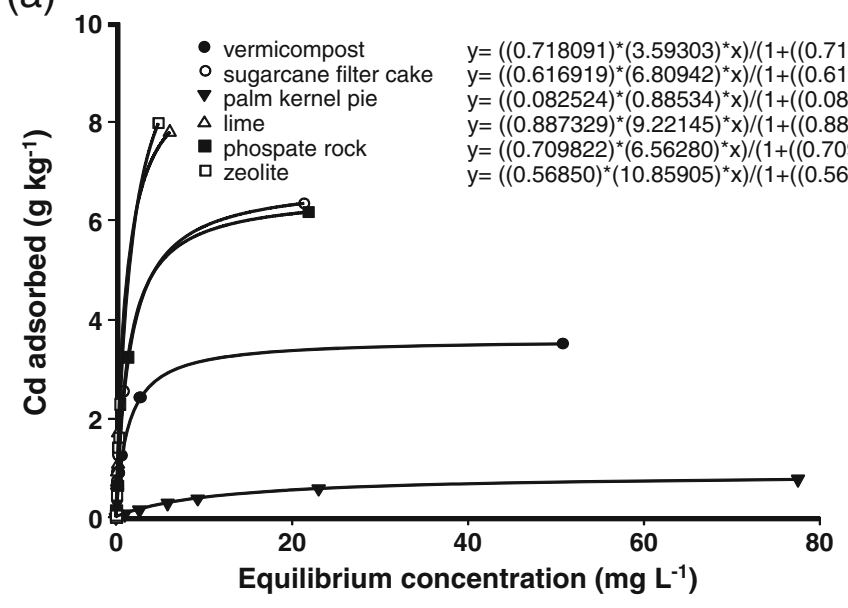

(b)

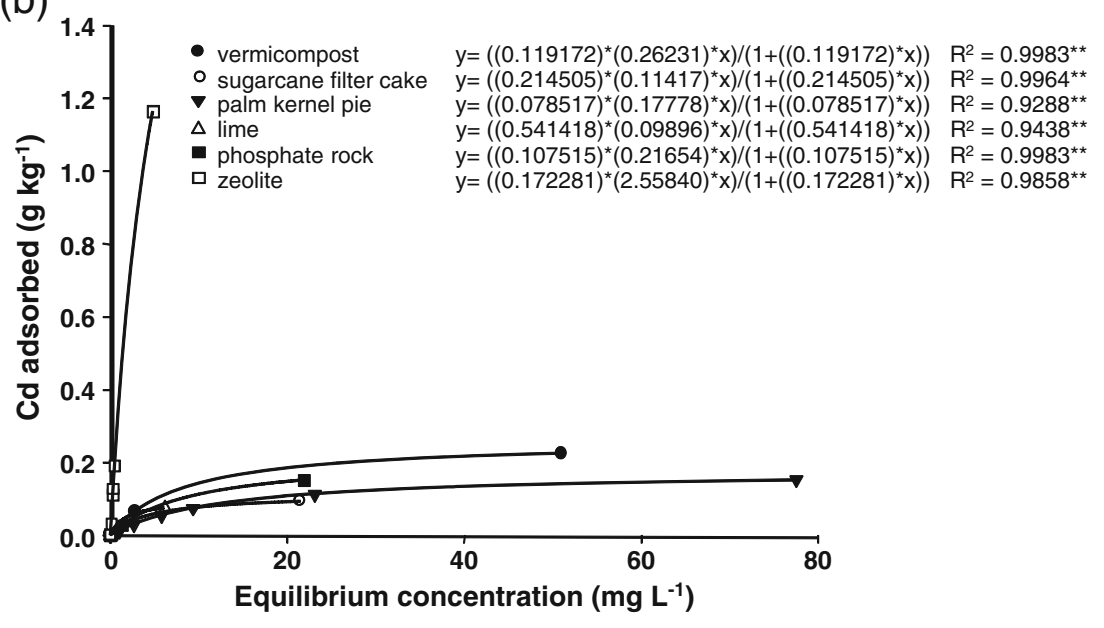

(c)

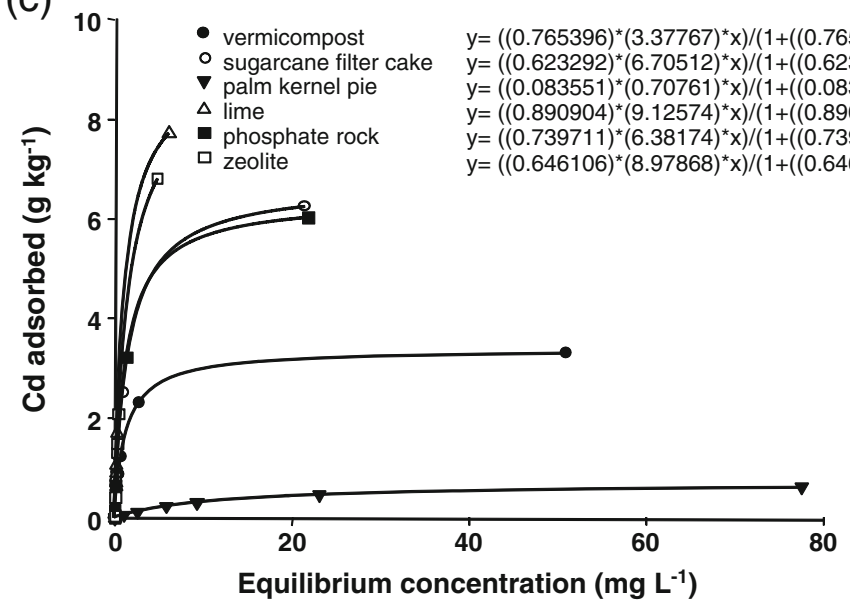

metal uptake by the adsorbent and the final metal concentration in synthetic phase, showing the sorption capacity of the adsorbent (Yun and Volesky 2003).
Sorption is a physical and/or chemical process in which a substance is accumulated at an interface between phases. Adsorption is the process through which a 
substance, originally present in one phase, is removed from that phase by accumulation at the interface between that phase and a separate (solid) phase. The overall rate of sorption of metals on an adsorbent depends on composition (density, surface area) of the adsorbent, concentration of adsorbate (metal ion) in solution, adsorbent to solution ratio, contact time history of the solute concentration with the adsorbent, $\mathrm{pH}$, temperature, and biodegradable characteristics of the adsorbent (Erses et al. 2005).

Small $a$ value $\left(0.08 \mathrm{Lmg}^{-1}\right)$ indicated that $\mathrm{Cd}^{2+}$ ions were bound weakly to palm kernel pie, while the values for the other soil amendments ranged from 0.57 to $0.89 \mathrm{Lmg}^{-1}$ (Fig. 1a). Although the energy of adsorption $a$ is related to metal fixation on substrate, via the reduction of metal mobility and availability to the environment, there is no direct relationship between $a$ and the maximum adsorption capacity $b$. For cadmium adsorption, for instance, the results indicated that zeolite adsorbed larger amounts of the metal, although the retention energy was low. It means that, although metal adsorption can be high, the metal availability could be enhanced since most of adsorption sites are of low affinity for the metal.

The experiments conducted with lime resulted in high $b$ and $a$ values, with quite good agreement for its use as a soil amendment to recovery of contaminated soil. The good effects of the application of lime to soil can be also due to the formation of $\mathrm{Cd}$ hydroxides and carbonates (Costa et al. 2009).

Charged solute species (ions) are attracted to the charged soil surface by electrostatic attraction and/or through the formation of specific bonds. Retention of charged solutes by charged surfaces is broadly grouped into specific and nonspecific retention (Bolan et al. 1999). In general terms, nonspecific sorption is a process in which the charge on the ions balances the charge on the soil particles through electrostatic attraction, whereas specific adsorption involves chemical bond formation between the ions and the sorption sites on the soil surface. In addition to specific and nonspecific sorption, other processes such as precipitation and complex formation also contribute to the retention (Adriano et al. 2004).

The data obtained for the nonspecific Cd adsorption fit the Langmuir isotherm model well (Fig. 1b). The maximum $\mathrm{Cd}$ nonspecific adsorption for zeolite $\left(2.56 \mathrm{mgkg}^{-1}\right)$ was elevated as compared with the other soil amendments. The relatively low value of the constant related to the energy of adsorption (0.17 $\left.\mathrm{L} \mathrm{mg}^{-1}\right)$ suggests that part of the adsorption sites of this mineral showed low affinity for $\mathrm{Cd}$. In this case, $\mathrm{Cd}$ might be available to plants after its immobilization. The mechanism of action of zeolite can be considered as purely electrostatic and might be related with the elevated cation exchange capacity of the adsorbent. This elevated cation exchange capacity is certainly due to inherent properties of zeolite such as its microporosity structure, among others (Aguiar and Novaes 2002).

The nonspecific $\mathrm{Cd}$ adsorption contribution of zeolite and palm kernel pie to the total $\mathrm{Cd}$ adsorption reached up to $24 \%$ and $20 \%$, respectively, while specific $\mathrm{Cd}$ adsorption was predominant for the other soil amendments examined.

The data presented in Fig. $1 \mathrm{~b}$ for the nonspecific $\mathrm{Cd}$ adsorption when Langmuir isotherm was used to model experimental data showed that the shape of the all soil amendments isotherms was of "L2" type, except for zeolite ("H1" type). The maximum nonspecific $\mathrm{Cd}$ adsorption capacity varied from 0.10 to $0.26 \mathrm{mgg}^{-1}$. Taking into account the nonspecific $\mathrm{Cd}$ adsorption, lime and palm kernel pie showed the higher and the lower constant related to the energy of adsorption, respectively (Fig. 1b). Similar results were also observed in the total $\mathrm{Cd}$ adsorption experiments, while there was no clear correlation affinity between these two types of $\mathrm{Cd}$ adsorption for the other soil amendments examined.

The equilibrium data for specific $\mathrm{Cd}$ adsorption on the soil amendments examined are shown in Fig. 1c. The shape of the isotherms was similar to those found in the total $\mathrm{Cd}$ adsorption experiments (Fig. 1a), and again, lime and zeolite were the soil amendments with the higher maximum Cd adsorption capacity. Among the organic amendments, sugarcane filter cake was most effective for $\mathrm{Cd}$ immobilization, whereas for the mineral amendments phosphate rock showed the lowest specific $\mathrm{Cd}$ adsorption.

The efficiency of Cd immobilization in situ on the selected soil amendments can be expressed by the maximum specific Cd sorption capacity, as follows: lime $>$ zeolite $>$ sugarcane filter cake $>$ phosphate rock $>$ vermicompost $>$ palm kernel pie (Fig. 1c). The constant related to the energy of adsorption in the specific $\mathrm{Cd}$ adsorption is an important parameter for the evaluation of soil amendment to retain the metal. The 
results suggest the following affinity order between $\mathrm{Cd}$ and the adsorbents: lime $>$ vermicompost $>$ phosphate rock $>$ zeolite $>$ sugarcane filter cake $>$ palm kernel pie. As in the case of the nonspecific $\mathrm{Cd}$ adsorption experiment (Fig. 1b), lime also showed high $b$ and $a$ values, with quite good agreement for its use as a soil amendment to recovery of contaminated soil.

Isotherms have been used to determine thermodynamic parameters of the process, for instance, free energy change (Hall et al. 1996). The Gibbs energy changes $\left(\Delta G^{\circ}\right)$ for the adsorption process was obtained at $25^{\circ} \mathrm{C}$ using the following equation:

$\Delta G^{\circ}=-R T \ln K$

where $R$ is the ideal gas constant $\left(8.314 \mathrm{Jmol}^{-1} \mathrm{~K}^{-1}\right)$ and $K$ is the equilibrium constant at temperature $T$ in $\mathrm{K}$ obtained from the Langmuir isotherms. The equilibrium constant can be represented as follows:

$K=\mathrm{C}_{\mathrm{s}} / \mathrm{C}_{\mathrm{e}}$

where $C_{\mathrm{s}}$ is the metal concentration on the adsorbent at equilibrium in $\mathrm{mgL}^{-1}$ and $C_{\mathrm{e}}$ is the equilibrium concentration of metal in solution in $\mathrm{mLL}^{-1}$

The $\Delta G^{\circ}$ values (in kilojoules per mole) were -2.87 , $-2.81,-0.33$ and -0.13 for $\mathrm{Cd}$ (II) adsorption on zeolite, lime, phosphate rock, and sugarcane filter cake, respectively (Table 2). The Gibbs free energy indicates the degree of spontaneity of the adsorption process, where more negative values reflect a more energetically favorable adsorption process. In the case, zeolite and lime presented less probability of $\mathrm{Cd}$ remobilization to the environment. It is noted that $\Delta G^{\mathrm{o}}$ up to $-20 \mathrm{kJmol}^{-1}$ are consistent with electrostatic interaction between sorption sites and the metal ion (physical adsorption), while $\Delta G^{\mathrm{o}}$ values more negative than $-40 \mathrm{kJmol}^{-1}$ involve charge sharing or transfer from the adsorbent surface to the metal ion to form a coordinate bond (chemical adsorption (Khan and Singh 1987).

Naturally, depending on the characteristics of the metal and the adsorbent surface, positive values of $\Delta G^{\mathrm{o}}$ can be reached which indicate weak chemical interactions and non-spontaneous process, such as reported for Co in Indian soils (Rawat et al. 1996). In such cases, mobilization of the metal to soil solution might occur. In our work, palm kernel pie had a positive value of $\Delta G^{\mathrm{o}}\left(+9.06 \mathrm{kJmol}^{-1}\right)$ and showed the second larger contribution (20\%) of the nonspecific $\mathrm{Cd}(\mathrm{II})$ adsorption in respect to total $\mathrm{Cd}(\mathrm{II})$ adsorption. On the other hand, vermicompost $\left(\Delta G^{\mathrm{o}}=+2.27 \mathrm{kJmol}^{-1}\right)$ followed a different pattern since a larger part of $\mathrm{Cd}$ was specifically adsorbed $\left(3.38 \mathrm{mgkg}^{-1}\right)$.

The Langmuir parameters can also be used to predict affinity between adsorbate and adsorbent using the dimensionless separation factor $R_{\mathrm{L}}$, which has been defined by Hall et al. (1996) as:

$R_{\mathrm{L}}=\frac{1}{1+b C_{0}}$

where $R_{\mathrm{L}}$ is the dimensionless separation factor, $C_{0}$ the initial concentration (milligrams per liter), and $b$ is the Langmuir constant (liters per milligram). The value of $R_{\mathrm{L}}$ can be used to predict whether a sorption system is "favorable" or "unfavorable" in accordance with the following criteria $-R_{\mathrm{L}}>1$, unfavorable sorption; $R_{\mathrm{L}}=1$, linear sorption; $0<R_{\mathrm{L}}<1$, favorable sorption; $R_{\mathrm{L}}=0$, irreversible.

The $R_{\mathrm{L}}$ values of $\mathrm{Cd}(\mathrm{II})$ adsorption on soil amendments ranged from 0.013 to 0.126 (Table 2). Sorption was favorable for $\mathrm{Cd}(\mathrm{II})$ because the $R_{\mathrm{L}}$ values were between 0 and 1 . Adsorption of $\mathrm{Cd}(\mathrm{II})$ on ground olive stones also resulted in $R_{\mathrm{L}}$ values between 0 and 1 (Rouibah et al. 2009). Values of $R_{\mathrm{L}}$ between 0.039 and 0.843 for $\mathrm{Al}(\mathrm{III})$ and between 0.060 and 0.519 for
Table 2 Gibbs free energy $\left(\Delta G^{\circ}\right)$ estimated with the mean values of the thermodynamic equilibrium constant $(K)$ and separation factor $\left(R_{\mathrm{L}}\right)$ for $\mathrm{Cd}(\mathrm{II})$ sorption on different soil amendments

\begin{tabular}{lrrr}
\hline Soil amendment & $\Delta G^{\mathrm{o}}\left(\mathrm{kJmol}^{-1}\right)$ & $\ln K$ & \multicolumn{1}{c}{$R_{\mathrm{L}}$} \\
\hline Vermicompost & $-0.91 \pm 1.76$ & 2.27 & 0.016 \\
Sugarcane filter cake & $0.05 \pm 1.27$ & -0.13 & 0.019 \\
Palm kernel pie & $-3.66 \pm 0.96$ & 9.06 & 0.126 \\
Lime & $1.14 \pm 0.89$ & -2.81 & 0.013 \\
Phosphate rock & $0.13 \pm 1.40$ & -0.33 & 0.016 \\
Zeolite & $1.16 \pm 0.66$ & -2.87 & 0.020 \\
\hline
\end{tabular}


$\mathrm{Fe}(\mathrm{II})$ adsorption in synthetic solution by vermicompost have been reported by Jordão et al. (2010).

Adsorption of $\mathrm{Cd}(\mathrm{II})$ to particles is presented in the form of a conditional particle-water distribution coefficient, $K_{\mathrm{d}}$, liters per gram:

$K_{\mathrm{d}}=\frac{\text { amount of metal adsorbed at equilibrium }\left(\mathrm{mg} \mathrm{g}^{-1}\right)}{\text { concentration of metal in the solution equilibrium }\left(\mathrm{mg} \mathrm{L}^{-1}\right)}$.

A high value of distribution coefficient is the characteristic of a good adsorbent (Kwon et al. 2005). The distribution coefficient $K_{\mathrm{d}}$ is a suitable index for comparing sorptive capacity of different soils or materials for any particular metal ion when measured under similar experimental conditions (Harter 1984). Also inherent in the thermodynamic definition of the $K_{\mathrm{d}}$ term are the assumptions that the reaction is independent of the contaminant concentration in the aqueous phase and that the system is reversible, i.e., that the desorption rate is equal to the adsorption rate (EPA 1999).

The distribution coefficients decrease with the increase of the electrolyte concentration (Table 3) and increase at greater $\mathrm{pH}$ values (Shah et al. 2011). In the present study, the $K_{\mathrm{d}}$ values were coherent with the data of the specific adsorption. The larger $K_{\mathrm{d}}$ values were found for lime and zeolite, indicating that these soil amendments have the greater affinity for $\mathrm{Cd}$. On the other hand, the smallest $K_{\mathrm{d}}$ value was obtained for palm kernel pie. According to Hooda (2010), inorganic materials present the same diffusion coefficient, while humic and fulvic complexes usually present smaller diffusion coefficients (from three to five times).

\section{Conclusions}

In this work, batch sorption experiments to evaluate the total, specific, and nonspecific sorption forms of $\mathrm{Cd}$ have been carried out in some mineral and organic soil amendments. Significant contribution made by this investigation includes the establishment that lime and zeolite presented less probability of $\mathrm{Cd}$ remobilization to the environment. The efficiency of $\mathrm{Cd}$ immobilization in situ of the other selected soil amendments can be expressed by the maximum specific $\mathrm{Cd}$ sorption capacity, as follows: sugarcane filter cake $>$ phosphate rock $>$ vermicompost $>$ palm kernel pie.

Zeolite presented elevated maximum $\mathrm{Cd}$ nonspecific sorption as compared with the other soil amendments. Thus, part of the sorption sites of this mineral presented low affinity for $\mathrm{Cd}$. This results in some of the already adsorbed Cd returning to solution, i.e., $\mathrm{Cd}$ might be easily redistributed in the environment.

Most studies do not take in to account the nonspecific sorption when evaluating promising materials for metal immobilization in contaminated soils. The investigations of the exchangeable form in sorption studies cannot be disregarded since it indicates the potentiality occurrence of desorption. The desorption phenomenon is responsible for the environmental implications due to the enhancement of metal contamination in soil. However, the specific metal sorption should be used as a suitable parameter for the choice of soil amendments in situ recovery of contaminated soil.

Table 3 Values of distribution coefficient $\left(K_{\mathrm{d}}\right)$ for the sorption of $\mathrm{Cd}(\mathrm{II})$ by mineral and organic soil amendments

\begin{tabular}{|c|c|c|c|c|c|c|c|c|c|c|c|}
\hline \multicolumn{2}{|c|}{ Vermicompost } & \multicolumn{2}{|c|}{ Sugarcane filter cake } & \multicolumn{2}{|c|}{ Palm kernel pie } & \multicolumn{2}{|l|}{ Lime } & \multicolumn{2}{|c|}{ Phosphate rock } & \multicolumn{2}{|c|}{ Zeolite } \\
\hline$C_{\mathrm{eq}}{ }^{\mathrm{a}}$ & $K_{\mathrm{d}}^{\mathrm{b}}$ & $C_{\mathrm{eq}}$ & $K_{\mathrm{d}}$ & $C_{\mathrm{eq}}$ & $K_{\mathrm{d}}$ & $C_{\mathrm{eq}}$ & $K_{\mathrm{d}}$ & $C_{\mathrm{eq}}$ & $K_{\mathrm{d}}$ & $C_{\mathrm{eq}}$ & $K_{\mathrm{d}}$ \\
\hline 0.145 & 2337 & 0.195 & 3750 & 0.993 & 68 & 0.111 & 7236 & 0.007 & 4634 & 0.006 & 6154 \\
\hline 0.262 & 2171 & 0.169 & 3805 & 2.578 & 60 & 0.364 & 7548 & 0.013 & 4615 & 0.073 & 5926 \\
\hline 0.452 & 1948 & 0.250 & 3640 & 5.783 & 49 & 0.905 & 7615 & 0.033 & 4553 & 0.263 & 5371 \\
\hline 0.728 & 1694 & 0.363 & 3432 & 9.280 & 41 & 1.105 & 6665 & 0.152 & 4206 & 0.306 & 5259 \\
\hline 2.806 & 856 & 0.959 & 2639 & 23.067 & 25 & 3.104 & 7379 & 1.375 & 2358 & 0.468 & 4877 \\
\hline 50.950 & 69 & 21.460 & 295 & 7.567 & 10 & 7.805 & 1274 & 21.867 & 282 & 4.834 & 1647 \\
\hline
\end{tabular}

${ }^{\mathrm{a}} C_{\mathrm{eq}}$, concentration of $\mathrm{Cd}$ at the equilibrium (milligrams per liter)

${ }^{\mathrm{b}} K_{\mathrm{d}}$ (liters per gram) 
Acknowledgments We thank the Instituto Nacional Autónomo de Investigaciones Agropecuarias (INIAP), Ecuador, for leave of absence. We also thank the Secretaria Nacional de Educación Superior, Ciencia, Tecnologia e Innovación, Ecuador, and the Fundação de Amparo à Pesquisa do Estado de Minas Gerais (FAPEMIG), Brazil, for financial support.

\section{References}

Adriano, D. C., Wenzel, W. W., Vangronsveld, J., \& Bolan, N. S. (2004). Role of assisted natural remediation in environmental cleanup. Geoderma, 122, 121-142.

Aguiar, P. M. M. R., \& Novaes, A. C. (2002). Remoção de metais pesados de efluentes industriais por aluminossilicatos. Química Nova, 25, 1145-1154.

Basta, N. T., \& McGrowen, S. L. (2004). Evaluation of chemical immobilization treatments for reducing heavy metal transport in a smelter-contaminated soil. Environmental Pollution, 127, 73-82.

Bolan, N. S., Naidu, R., Syers, J. K., \& Tillman, R. W. (1999). Surface charge and solute interactions in soils. Advances in Agronomy, 67, 88-141.

Brown, S., Christensen, B., Lombi, E., McLaughlin, M., McGrath, S., Colpaert, J., et al. (2005). An interlaboratory study to test the ability of amendments to reduce the availability of $\mathrm{Cd}, \mathrm{Pb}$, and $\mathrm{Zn}$ in situ. Environmental Pollution, 138, 34-45.

Costa, S. E. T., Guillerme, G. L. R., Curi, N., Lopes, G., Visioli, L. E., \& Oliveira, A. L. C. (2009). Caracterização de subproduto da indústria do alumínio e seu uso na retenção de cádmio e chumbo em sistemas monoelementares. Quimica Nova, 32, 868-874.

Dias, N. M. P., Alleoni, L. R. F., Casagrande, J. C., \& Camargo, O. A. (2001). Isotermas de adsorção de cádmio em solos ácricos. Revista Brasileira de Engenharia Agrícola e Ambiental, 5, 229-234.

EPA (Environmental Protection Agency). (1999). Understanding variation in partition coefficient, $\mathrm{Kd}$, values. Volume I: The Kd model, methods of measurement, and application of chemical reaction codes. United States.

Erses, A. S., Fazal, M. A., Onaya, T. T., \& Craig, W. H. (2005). Determination of solidwaste sorption capacity for selected heavy metals in landfills. Journal of Hazardous Materials, $121,223-232$.

Giles, C. H., \& Smith, D. A. (1974). General treatment and classification of the solute sorption isotherms. Journal of Colloid and Interface Science, 47, 755-765.

Hall, K. R., Eagleton, L. C., Acrivos, A., \& Vermeulen, T. (1996). Pore- and solid-diffusion kinetics in fixed bed adsorption under constant-pattern conditions. Industrial and Engineering Chemistry Fundamentals, 5, 212-223.

Hamon, R. E., McLaughlin, M. J., \& Cozens, G. (2002). Mechanisms of attenuation of metal availability in situ remediation treatments. Environmental Science \& Technology, 36, 3991-3996.
Harter, R. D. (1984). Curve-fit errors in Langmuir adsorption maxima. Soil Science Society of America Journal, 48, 749752.

Harter, R. D., \& Naidu, R. (2001). An assessment of environmental and solution parameter impact on trace-metal sorption by soils. Soil Science Society of America Journal, 65, 597-612.

Hooda, P. S. (2010). Basic principles, processes, sampling and analytical aspects. In P. S. Hooda (Ed.), Trace elements in soil. London: Willey.

Jordão, C. P., Fernandes, R. B. A., Ribeiro, K. L., Barros, P. M., Fontes, M. P. F., \& Souza, F. M. P. (2010). A study on Al (III) and $\mathrm{Fe}(\mathrm{II})$ ions sorption by cattle manure vermicompost. Water, Air, and Soil Pollution, 210, 51-61.

Kabata-Pendias, A. (2011). Trace elements in soils and plants. Florida: CRC Press.

Khan, A. A., \& Singh, R. P. (1987). Adsorption thermodynamics of carbofuran on $\mathrm{Sn}(\mathrm{IV})$ arsenosilicate in $\mathrm{H}^{+}, \mathrm{Na}^{+}$and $\mathrm{Ca}^{2+}$ forms. Colloids and Surfaces, 24, 33-42.

Kwon, J. S., Yun, S. T., Kim, S. O., Mayer, B., \& Hutcheon, I. (2005). Sorption of $\mathrm{Zn}$ (II) in aqueous solutions by scoria. Chemosphere, 60, 1416-1426.

Mendonça, E. S., \& Matos, E. S. (2005). Matéria Orgánica do Solo: Métodos de Análise. Viçosa: Imprensa Universitária da Universidade Federal de Viçosa.

Oste, L., Lexmond, T. M., \& Van Riemsdijk, W. H. (2002). Metal immobilization in soils using synthetic zeolites. Journal of Environmental Quality, 31, 813-821.

Pierangeli, M. A. P., Guillerme, L. R. G., Curi, N., Costa, E. T. S., Lima, J. M., Melo Marques, J. J. G., et al. (2007). Individual and competitive sorption of heavy metals in oxisols with contrasting mineralogy. Revista Brasileira de Ciência do Solo, 31, 819-826.

Pino, G. H., \& Torem, M. L. (2011). Aspectos fundamentais da biossorção de metais não ferrosos-estudo de caso. Tecnologia em Metalurgia, Materiais e Mineração, 8, 57-63.

Rao, S. K., Anand, S., \& Venkateswarlu, P. (2010). Adsorption of cadmium (II) ions from aqueous solution by Tectona grandis L:F: (Teak leaves powder). Bioresources, 5, 438454.

Rawat, J. P., Umar Iraqi, S. M., \& Singh, R. P. (1996). Sorption equilibria of cobalt (II) on two types of Indian soils-The natural ion exchangers. Colloids and Surfaces, 117, 183188.

Rouibah, K., Meniai, A. H., Rouibah, M. T., \& Deffous, L. (2009). Elimination of chromium (VI) and cadmium (II) from aqueous solutions by adsorption olive stones. The Open Chemical Engineering Journal, 3, 41-48.

Sanchez, R. A., \& Espósito, B. P. (2011). Preparation of sugarcane bagasse modified with the thiophosphoryl function and its capacity for cadmium adsorption. Bioresources, 6 , 2448-2459.

Shah, B. A., Shah, A. V., \& Tailor, R. V. (2011). Characterization of hydroxybenzoic acid chelating resins: Equilibrium, kinetics, and isotherm profiles for $\mathrm{Cd}$ (II) and $\mathrm{Pb}$ (II) uptake. Journal of the Serbian Chemical Society, 76, 903-922. 
Silveira, M. L., Alleoni, F. L. R., \& Chang, A. (2008). Condicionadores químicos de solo e retenção e distribuição de cádio, zinco e cobre em Latossolos tratados com biossólido. Revista Brasileira de Ciencia do Solo, 32, 1087-1098.

Singh, B. A., \& Oste, L. (2001). In situ immobilization of metals in contaminated or naturally metal-rich soils. Environmental Reviews, 9, 81-97.

Sopper, W. E. (1993). Municipal sludge use for land reclamation. Ann Arbor: Lewis Publishers.
Tunali, S., \& Akar, T. (2006). Zn(II) biosorption properties of Botrytis cinerea biomass. Journal of Hazardous Materials, B131, 137-145.

Wahba, M. M., \& Zaghloul, A. M. (2007). Adsorption characteristics of some heavy metals by some soil minerals. Journal of Applied Science Research, 3, 421-426.

Yun, Y. S., \& Volesky, B. (2003). Modeling of lithium interference in cadmium biosorption. Environmental Science \& Technology, 37, 3601-3608. 